JST 8 (1) (2019)
JURNAL SENI TARI
Terakreditasi SINTA 5
htt/iournal.unnes.ac.id/siu/index.php/ist

\title{
Kesenian Kuda Lumping di Paguyuban Genjring Kuda Lumping Sokoaji: Kajian Enkulturasi Budaya
}

\author{
Sofia Rachmawati ${ }^{1}$, Hartono $^{2}$ \\ Jurusan Pendidikan Seni Drama Tari dan Musik, Fakultas Bahasa dan Seni, Universitas \\ Negeri Semarang, Indonesia.
}

\begin{abstract}
Info Artikel
Diterima : 15 Mei 2019

Disetujui : 22 Juni 2019

Dipublikasikan : 23 Juli 2019

Keywords:

Enkulturation; Kuda

Lumping Art; Performing

Arts

Abstrak

Tujuan penelitian untuk mendeskripsikan enkulturasi budaya dengan kajian pokok bentuk pertunjukan kesenian Kuda Lumping Sokoaji dan proses enkulturasi budaya di Paguyuban Genjring Sokoaji. Metode penelitian kualitatif digunakan peneliti untuk mengkaji enkulturasi budaya dengan menggunakan pendekatan antropologi prehistori dan pendekatan etik emik. Teknik pengumpulan data yang digunakan yaitu: observasi, wawancara dan dokumentasi, sedangkan teknik analisis data yang digunakan meliputi reduksi data, penyajian data dan verifikasi/kesimpulan. Penelitian ini menjelaskan bahwa proses enkulturasi di Paguyuban Genjring Sokoaji terjadi secara turun-temurun melalui keluarga, lingkungan, dan pembelajaran. Anggota Paguyuban Genjring Sokoaji mengenkulturasi kesenian Kuda Lumping secara tradisional dan melalui proses pembelajaran informal.

\section{Abstract}

The purposes of the study were to describe cultural enculturation with a study of the main forms of Kuda Lumping Sokoaji Performing arts and cultural enculturation processes in Paguyuban Genjring Sokoaji. Qualitative descriptive research method is used by researchers to examine cultural enculturation by using prehistoric anthropological approaches and emic ethical approaches. Data collection techniques used: observation, interviews and documentation, while the data analysis techniques used data reduction, data presentation and verification / conclusions. This study explains that the enculturation process in Paguyuban Genjring Sokoaji takes place from generation to generation through family, environment, and learning. Members of the Paguyuban Genjring Sokoaji traditionally cultivate Kesenian Kuda Lumping and through informal learning processes.
\end{abstract}

C2019 Universitas Negeri Semarang

\footnotetext{
Alamat korespondensi:

Gedung B2 Lantai 1, FBS, UNNES

Kampus Sekaran, Gunung Pati, Semarang 50229

Email : 1.sofiarachmawati97@gmail.com
}

ISSN 2503-2585

2. hartono sukoreio@mail.unnes.ac.id 


\section{PENDAHULUAN}

Kuda Lumping merupakan kesenian rakyat yang keberadaanya tetap eksis dari dulu hingga sekarang. Kuda Lumping biasanya hadir pada acara hajatan, khitanan, atau perayaan lainya. Kuda Lumping identik dengan penari laki-laki yang menari menggunakan propeeti anyaman bambu berbentuk kuda dan mengalami kesurupan atau trans. Kuda Lumping juga identik dengan atraksi debus seperti memakan beling dan memakan ayam mentah. Kuda Lumping memiliki beberapa sebutan dari berbagai daerah, yaitu: Jathilan, Ebeg, dan Jaran Kepang. Kabupaten Pekalongan memiliki kesenian Kuda Lumping yang keberadaanya sejak dulu sampai sekarang masih sering dipentaskan. Kesenian Kuda Lumping yang masih eksis di Kabupaten Pekalongan yaitu Kesenian Kuda Lumping di Paguyuban Genjring Sokoaji.

Paguyuban Genjring Sokoaji merupakan paguyuban kesenian Kuda Lumping yang berdiri sejak tahun 1995 dan diketuai oleh Bapak Nasirin. Nama Paguyuban Genjring Sokoaji memiliki arti tersendiri, yaitu genjring berarti terbang. Terbang bukan berarti kata kerja namun terbang merupakan alat musik terbuat dari kayu berbentuk lingkaran dengan kulit lembu yang dikaitkan diatasnya. Kulit lembu dikaitkan menggunakan paku payung di keliling lingkaran kayu. Cara memainkan terbang adalah dengan memukulnya. Suara yang dihasilkan terbang bervariasi tergantung ukuran terbang, teknik, dan cara memainkan terbang itu sendiri. Terbang biasanya disebut juga rebana atau marawis. Terbang biasa digunakan pada musik yang beraliran islami. Paguyuban Genjring Sokoaji menggunakan terbang sebagai salah satu alat musik selain gamelan dan angklung. Soko berarti tiang yang memiliki makna ngedeg roso dan aji berarti orang yang suka ngajeni atau menghargai. Sokoaji berarti tiang kemuliaan.

$$
\text { Paguyuban Kuda Lumping }
$$

Genjring Sokoaji telah terdaftar dan resmi menjadi kesenian Kuda Lumping yang ada di Kabupaten Pekalongan. Surat keterangan pengesahan menjadi bukti bahwa Paguyuban Genjring Sokoaji merupakan paguyuban resmi di bawah naungan Dewan Kesenian Daerah Kabupaten Pekalongan. Paguyuban Genjring Sokoaji memiliki anggota aktif sebanyak 64 orang yang terdiri dari remaja berumur 18 tahun hingga dewasa berumur 40 tahun. Anggota Paguyuban Genjring Sokoaji tidak hanya terdiri dari orang Desa Sokoyoso saja, namun dari desa lain seperti Desa Kulu dan Desa Pringsurat.

Peneliti memilih Paguyuban Genjring Sokoaji sebagai lokasi penelitian karena ke-eksisan Paguyuban Genjring Sokoaji yang sejak tahun 1995 sampai sekarang masih bertahan. Peneliti ingin mengetahui faktor apa yang membuat Paguyuban Genjring Sokoaji masih eksis dan bertahan ditengah era modernisasi yang semakin meningkat di masyarakat. Adanya usaha pewarisan budaya menjadi salah satu upaya masyarakat untuk menjaga keberadaan Paguyuban Genjring Sokoaji. Salah satu upaya pewarisan yang terjadi di Paguyuban Genjring Sokoaji yaitu enkulturasi.

Enkulturasi sebagai bagian dari pewarisan budaya tidak dapat bertahan dan berkembang jika tidak ada dukungan masyarakat luas dan tidak menjadi bagian nyata dari kehidupan masyarakatnya sendiri. Proses enkulturasi seorang individu yaitu mempelajari dan menyesuaikan alam pikiran serta sikapnya dengan adat-adat, sistem norma, dan peraturan-peraturan yang hidup dalam kebudayaannya (Koentjaraningrat 1990: 233). Proses enkulturasi dilakukan secara generasi ke generasi melalui proses pembelajaran informal. Seseorang dapat melihat, meniru, dan menyesuaikan diri terhadap kebudayaan yang dipelajari secara turuntemurun dari generasi ke generasi berikutnya.

Proses enkulturasi erat hubunganya dengan pembelajaran, seperti yang dijelaskan Kodiran dalam artikel yang berjudul "Pewarisan Budaya dan Kepribadian" bahwa kebudayaan yang berupa nilai, ketrerampilan, norma, adat istiadat diturunkan dari generasi ke generasi berikutnya melalui proses 
pembelajaran baik secara formal dan informal (enkulturasi dan sosialisasi). Orang mempelajari kebudayaannya dengan menjadi besar didalamnya. Ralph Linton menyebut kebudayaan sebagai "warisan sosial" umat manusia. Proses penerusan kebudayaan dari generasi satu kepada generasi yang lain disebut enkulturasi.

Proses belajar ini biasanya dimulai sejak anak lahir sampai menjelang akhir hayatnya. Ia mempelajari apa yang terjadi mulai di lingkungan keluarga, tetangga, sampai kepada lingkungan sosial yang lebih luas. Ketika seseorang berniat mempelajari suatu kesenian, seseorang tidak hanya mencari tahu keseniannya namun harus beradaptasi dengan norma yang berlaku dalam kesenian tersebut. Mempelajari sikap, nilai, serta kebiasaan yang dilakukan di sekitar lingkungan kebudayaanya. Maka proses belajar enkulturasi memerlukan waktu yang tidak sedikit bahkan hingga bertahun-tahun sehingga penyesuaian pada masing-masing kebudayaan berjalan dengan efektif.

Proses enkulturasi dimulai sejak kecil, seorang individu meniru saja segala sesuatu tindakan, norma, aturan dari dalam keluarganya kemudian temantemannya. Tindakan meniru berkali-kali dilakulan hingga menjadi sebuah pola yang mantap dan menjadi aturan yang mengatur bagaimana individu akan bersikap dan dibudayakan. Sebagai contoh orang Indonesia ketika berpergian harus membawakan oleh-oleh untuk kerabat dekat rumahnya. Memberi oleholeh tadi dibudayakan berdasarkan ajaran sopan santun dari orangtuanya. Namun, dalam suatu masyarakat adapula yang mengalami kendala dalam proses internalisasi, sosialisasi, dan enkulturasinya. Setiap individu memiliki perbedaan pada proses enkulturasinya tak terkecuali di Paguyuban Genjring Sokoaji. Enkulturasi terjadi sesuai dengan proses, waktu, serta faktor yang mendukung enkulturasi setiap individu. Adanya proses melihat, meniru, dan mencoba yang dilakukan berulang-ulang hingga menjadi sebuah pola kebudayaan yang mantap. Seperti halnya pada penelitian yang dilakukan oleh Agus
Cahyono dalam jurnal Harmonia tahun 2016 dengan judul "Pola Pewarisan Nilai-Nilai Kesenian Tayub".

Agus Cahyono menjelaskan bahwa pewarisan tayub menggunakan metode yang disengaja tanpa disadari oleh sumber belajar yaitu para tledhek senior kepada subjek didik atau wurukan. Seorang wurukan biasanya diberi contoh langsung dengan cara menirukan atau mengikuti (ngunthul) di belakang tledhek senior, bagaimana seharusnya berbusana, menggunakan rias, menari, melantunkan tembang sesuai dengan iringan. Tanpa disadari para tledhek senior menjadi contoh oleh anak-anak calon tledhek atau wurukan, dalam hal ini disebut metode imitasi/identifikasi. Jika anak hanya ingin sekedar meniru aspek luar dari tokoh dan berlangsung dalam waktu singkat disebut imitasi. Sebaliknya apabila anak ingin menjadikan dirinya sama atau identik maka terjadi peniruan lebih dalam disebut identifikasi. Metode selanjutnya yaitu metode pelaziman dalam pewarisan tayub adalah suatu cara membawa anak untuk mengenal, menyenangi dan mencoba pekerjaan melalui proses pembiasaan yang dilakukan oleh orang tua, tledhek senior, atau komunitas tayub yang telah dewasa. Hal ini biasanya terjadi pada anak-anak dari keluarga kesenian tayub dari penari atau pengrawit.

Konsep peniruan yang terjadi pada proses pewarisan Tayub juga terjadi pada proses pewarisan kesenian Kuda Lumping. Adanya proses pembiasaan yang dilakukan orangtua untuk mengenalkan budaya yang dilakukan secara terus menerus terjadi pada Kiki Sunardi selaku pengrawit di Paguyuban Genjring Sokoaji. Sejak Kiki berusia 5tahun, dirinnya sering diajak oleh ayahnya yaitu Bapak Priyatno untuk melihat kesenian Kuda Lumping. Bapak Priyatno mengajak Kiki untuk melihat kesenian Kuda Lumping bukan sematamata hanya ingin memperkenalkan, Bapak Priyatno selaku pawang di kesenian Kuda Lumping tersebut sekaligus ingin mewariskan ilmunya sebagai pawang kepada sang anak Kiki Sunardi. Namun, usaha Bapak Priyatno tidak sesuai dengan harapan. Kiki 
Sunardi lebih memilih menjadi pengrawit daripada menjadi seorang pawang seperti ayahnya. Menurut Bapak Priyatno, hal ini terjadi karena Kiki selalu didudukkan di tengah-tengah pengrawit pada saat Bapak Priyatno sedang bertugas sehingga dirinya lebih fokus pada permainan gamelan daripada teknik pawang yang dilakukan Bapak Priyatno. Proses enkulturasi seperti ini berlangsung secara nonformal dan spontan agtau tidak disengaja.

Hal ini sehubungan dengan penelitian oleh Kadiran dalam jurnal Humaniora yang berjudul "Pewarisan Budaya dan Kepribadianya" pada tahun 2004. Kadiran menjelaskan bahwa proses pewarisan budaya dapat berlangsung secara formal maupun informal. Secara formal umumnya dilakukan melalui program pendidikan seperti sekolah, perguruan tinggi, serta tempat pelatihan kerja atau ketrampilan seperti sanggar, komunitas, dan paguyuban. Secara informal dilakukan melalui proses enkulturasi dan sosialisasi.

Enkulturasi merupakan suatu proses penerusan kebudayaan kepada seorang individu yang dimulai segera setelah seseorang dilahirkan, yaitu pada saat kesadaran diri mulai bersangkutan mulai tumbuh dan berkembang. Agar kesadaran diri itu dapat berfungsi, seorang individu harus dilengkapi dengan lingkungan sosialnya. Adapun pewarisan budaya yang dilakukan melaui proses sosialisasi sangat erat berkaitan dengan proses belajar yang berkaitan dengan sistem sosial. Perlu diketahui bahwa proses sosialisasi pada suatu masyarakat berbeda-beda atau tidak sama. Adanya perbedaan pada proses pewarisan budaya serta latar belakang budaya menimbulkan kepribadian yang berbeda pula. Pembentukan kebudayaan ditentukan pula oleh lingkungan sosial-budaya melalui proses pembelajaran, peniruan, dan penyesuaian terhadap perilaku serta tradisi masyarakatnya yang berlangsung secara turun-temurun dari generasi ke generasi berikutnya.

Konsep enkulturasi r yang
dijelaskan Kadiran bahwa proses
enkulturasi
informal berbedalui antar

dengan individu yang lain. Perbedaan proses enkulturasi juga menyebabkan kepribadian individu yang berbeda pula, seperti proses enkulturasi yang terjadi di Paguyuban Genjring Sokoaji. Setiap anggota Paguyuban Genjring Kuda Lumping Sokoaji memiliki proses enkulturasinya masing-masing dan menghasilkan kepribadian atau hasil enkulturasi yang berbeda pula. Peneliti membuktikan hal ini dengan meneliti satu anggota Paguyuban Genjring Sokoaji sesuai bidangnya masing-masing yaitu Nikma Maulandari selaku penari, Kiki Sunardi selaku pengrawit, dan Poerwanto selaku pemain Kuda Lumping. Mereka memiliki perbedaan dalam proses enkulturasi di Paguyuban Genjring Kuda Lumping Sokoaji yang menyebabkan mereka tidak bisa melakukan apa yang dilakukan oleh teman diluar bidangnya.

Disimpulkan bahwa proses enkulturasi yang terjadi di Paguyuban Genjring Sokoaji merupakan gabungan dari konsep enkulturasi yang dijelaskan oleh Agus Cahyono dan Kadiran dalam jurnalnya. Penelitian proses enkulturasi di Paguyuban Genjring Sokoaji merupakan penelitian yang sebelumnya belum pernah diteliti, adapun persamaan yang ditemukan pada penelitian terdahulu yaitu teori serta metode yang digunakan dalam pencarian data di lapangan. Beberapa teori yang digunakan peneliti guna mengkaji enkulturasi di Paguyuban Genjring Sokoaji yaitu; teori enkulturasi dan bentuk pertunjukan.

Peneliti menyimpulkan proses enkulturasi dapat terjadi melalui dua tahap yaitu: 1) secara tradisional, 2) secara modern. Proses enkulturasi secara tradisional melalui keluarga, lingkungan masyarakat, dan lembaga adat. Proses enkulturasi secara modern terjadi melalui organisasi kelompok sosial dan media massa. Selain teori enkulturasi, peneliti juga menggunakan teori bentuk pertunjukan sebagai hasil dari enkulturasi yang telah berlangsung.

Setelah penjelasan diatas, muncul dua rumusan masalah dalam penelitian kajian enkulturasi budaya ini yaitu: bagaimana bentuk pertunjukan kesenian Kuda Lumping di Paguyuban Genjring 
Sokoaji dan bagaimana proses enkulturasi kesenian Kuda Lumping di Paguyuban Genjring Sokoaji..

\section{METODE}

Penelitian ini menggunakan tiga pendekatan yaitu deskriptif kualitatif, pendekatan antropologi prehistori dan etik emik. Pendekatan deskriptif kualitatif digunakan peneliti karena hasil penelitian yang diperoleh dari penelitian kualitatif berupa deskripsi atau catatan lapangan.

Data dalam penelitian ini berupa teori yang memperkuat penelitian, hasil observasi, dan hasil wawancara oleh perangkat dan anggota kesenian dalam bentuk teks atau rekaman, foto dan video proses latihan dan pementasan. Hasil pendekatan dalam penelitian ini berupa data-data penelitian yang meliputi deksripsi proses latihan dan pertunjukan Kesenian Kuda Lumping Sokoaji.

Pendekatan pada penelitian ini yaitu antropologi prehistori. Peneliti menggunakan pendekatan antropologi prehistori karena kajian enkulturasi budaya merupakan penelitian yang membahas mengenai sejarah atau asal usul. Pendekatan antropologi digunakan untuk menganalisa perilaku masyarakat dalam mewariskan Kuda Lumping Sokoaji. Prehistori digunakan untuk meneliti sejarah bentuk pertunjukan kesenian Kuda Lumping Sokoaji.

Pendekatan etik emik digunakan peneliti karena penggunaan istilah, simbol, atau perumpaan yang sudah berkembang di masyarakat. Pendekatan Kesenian Kuda Lumping Sokoaji menggunakan pendekatan emik karena adanya penggunaan istilah-istilah alur pertunjukan dan gerak yang digunakan sudah ada dalam lingkungan masyarakat seperti: ukel, seblak, dan geyol. Pendekatan etik diperlukan apabila tidak ditemukan istilah-istilah dalam pendekatan emik, sehingga peneliti harus membuat istilah sebagai perkiraan seperti: macanan, dan jamang.

Teknik pengumpulan data dilakukan peneliti dengan menggunakan teknik observasi, wawancara, dan dokumentasi. Hasil observasi berupa data mengenai gambaran umum lokasi penelitian, kondisi demografi dan geografi Desa Sokoyoso, proses latihan, dan pementasan. Observasi dilakukan pada bulan Juli-September 2018, yang diketahui oleh Pemerintah Desa Sokoyoso, masyarakat Desa Sokoyoso yang meliputi tokoh masyarakat dan pelaku Paguyuban Genjring Sokoaji.

Hasil wawancara berupa data mengenai proses enkulturasi budaya dan bentuk pertunjukan kesenian Kuda Lumping di Paguyuban Genjring Soikoaji. Wawancara dilakukan dengan Bapak Supomo selaku ketua Paguyuban Genjring Sokoaji, Poerwanto, Kiki Sunardi, Nikma Maulandari selaku anggota Paguyuban Genjring Sokoaji, dan Bapak Amin selaku sekretaris Paguyuban Genjring Sokoaji. Hasil dokumentasi berupa foto dan video pada saat latihan, dan foto serta video pementasan Kuda Lumping Sokoaji.

Peneliti menggunakan triangulasi untuk keabsahan data. Triangulasi teori, metode, dan teknik dilakukan dengan memanfaatkan berbagai teori, metode, dan teknik untuk menganalisis masalah yang sama. Triangulasi yang digunakan peneliti dalam mengkaji enkulturasi kesenian Kuda Lumping Sokoaji yaitu triangulasi sumber dan triangulasi teknik. Triangulasi sumber, peneliti mencari data mengenai proses enkulturasi dengan beberapa sumber yaitu Poerwanto, Kiki, dan Nikma Maulandari. Peneliti juga melakukan triangulasi teknik, kepada ketiga narasumber peneliti menggunakan beberapa teknik yaitu observasi, wawancara, dan dokumentasi. Teknik keabsahan data dilakukan langsung ke lokasi penelitian yaitu di Paguyuban Genjring Kuda Lumping Sokoaji.

\section{HASIL DAN PEMBAHASAN}

\section{Enkulturasi Budaya}

Enkulturasi memberikan ciri khusus untuk membedakan manusia dengan makhluk lain dengan mengunakan pengalaman-pengalaman hidupnya. Anak ketika baru lahir tidak memiliki kebiasaan (budaya) yang begitu saja turun-temurun dari satu generasi ke generasi lain, maka harus dikondisikan ke 
dalam hubungan kebergantungan antara orangtua dan anak, dengan anggota keluarga lain dan lingkungan yang mendukungnya baik dalam keluarga maupun lingkungan yang lebih luas (masyarakat).

Enkulturasi adalah proses belajar suatu kebudayaan atau pembudayaan yaitu seseorang harus mempelajari dan menyesuaikan sikap dan alam berpikirnya dengan sistem norma yang hidup dalam kebudayaanya (Poerwanto 2000: 89). Proses enkulturasi dekat dengan pembelajaran, seperti yang dijelaskan Kodiran dalam artikel yang berjudul "Pewarisan Budaya dan Kepribadian" bahwa kebudayaan yang berupa nilai, ketrerampilan, norma, adat istiadat diturunkan dari generasi ke generasi berikutnya melalui proses pembelajaran baik secara formal dan informal (enkulturasi dan sosialisasi). Proses pembelajaran pada proses enkulturasi dimaksudkan sebagai proses peralihan keterampilan, nilai, adat istiadat melalui berbagai cara seperti melihat, mendengar, menirukan. Seperti halnya model pembelajaran yang sering dilakukan antara guru dan murid yaitu demonstrasi, imitasi, diskusi, dan yang lain. Menurut Sunaryo (1989: 2) pembelajaran adalah perpaduan aktivitas yaitu mengajar dan aktivitas belajar. Belajar adalah suatu kegiatan dimana seseorang membuat atau menghasilkan suatu perubahan tingkah laku yang ada dalam dirinya, seperti: pengetahuan, sikap, atau keterampilan. Gagne dalam Mudjiono (1994: 9) menjelaskan belajar merupakan kegiatan yang kompleks.

Secara historis, proses enkulturasi Paguyuban Genjring Sokoaji berlangsung selama 23 tahun. Perjalanan waktu yang cukup panjang bagi sebuah kesenian. Paguyuban Genjring Sokoaji masih bertahan hingga sekarang ini karena melalui suatu proses enkulturasi antar generasi. Rendahnya pendidikan di Desa Sokoyoso membuat informasi yang masuk sedikit terhambat. Begitupun dengan kesenian, Kuda Lumping dianggap paling cocok di masyarakat Desa Sokoyoso walaupun di Kota Pekalongan ada kesenian Sintren. Kuda Lumping sudah sangat dekat dengan masyarakat Desa Sokoyoso. Sejak tahun 1995 Kuda Lumping merupakan satusatunya kesenian berkembang dan diterima oleh masyarakat Desa Sokoyoso.

Kuda Lumping sudah menjadi bahan pokok bagi masyarakat Sokoyoso terutama bagi remaja. Sejak kecil anggota paguyuban seperti Kiki, Perwanto, dan Nikma sudah kenal dekat dengan Kuda Lumping Sokoaji. Mereka sering melihat pementasan Paguyuban Genjring Sokoaji yang saat itu masih Genjring Sokoyoso. Mulai dari sinilah proses enkulturasi mulai berlangsung. Enkulturasi budaya di Paguyuban Genjring Sokoaji terjadi secara tradisional dan modern melalui keluarga, masyarakat, latihan, dan pertunjukan.

\section{Bentuk Pertunjukan}

Bentuk pertunjukan tari meliputi kelengkapan sajian tari yang meliputi musik, tema, tata busana, tata rias, pentas, tata lampu/cahaya dan suara, serta property Jazuli (2016: 60-63). Elemen-elemen pokok dalam seni Sendratari terdiri dari penari (aktor/aktrisnya), sutradara, lakon atau cerita, tata rias dan busana, musik pengiring, dan tata panggung (Sumaryono 2011: 160-163).

Bentuk pertunjukan kesenian Kuda Lumping Sokoaji di Desa Sokoyoso Kecamatan Kajen Kabupaten Pekalongan merupakan hasil dari proses enkulturasi yang telah berlangsung sejak dulu. Bentuk petunjukan kesenian Kuda Lumping Sokoaji merupakan pengembangan dari bentuk pertunjukan kesenian Kuda Lumping yang dahulu yaitu Genjring Sokoyoso. Adanya perbedaan diantaranya pada waktu pertunjukan, lakon atau pemain, serta atraksi di pertunjukan kesenian Kuda Lumping Sokoaji. Berikut dijelaskan elemen-elemen bentuk pertunjukan kesenian Kuda Lumping Sokoaji.

Tema merupakan ide dasar atau pokok pikiran dalam suatu pertunjukan. Tema yang terdapat dalam pertunjukan keseniana Kuda Lumping Sokoaji yaitu kehidupan. Tema kehidupan dalam kesenian Kuda Lumping Sokoaji dilihat 
dari alur cerita kesenian Kuda Lumping Sokoaji yang menceritakan tentang keserakahan manusia dalam hidupnya. Pertunjukan kesenian Kuda Lumping Sokoaji memiliki alur pertunjukan dimulai dari arakarakan, genjringan, tari pembuka, Kuda Lumping, barong, jaran kepang, sintren lais, angklung, macanan, dedemit.

Penari di Paguyuban Genjring Sokoaji terdiri dari remaja Desa Sokoyoso yang memiliki umur dari 18 tahun hingga 27 tahun. Penari laki-laki dijadikan sebagai Pemain Kuda Lumping, pemain kuda kepang, pemain barongan, pemain topeng, lais, dan demit. Penari perempuan dijadikan sebagai penari Sokoaji yang menarikan berbagai macam tarian sebagai pembuka di awal pertunjukan. Tari Sokoaji merupakan tarian wajib yang harus ditarikan oleh penari Sokoaji. Ragam gerak yang terdapat pada kesenian Kuda Lumping Sokoaji sebagian besar gerak nonrepresentatif. Gerak non-representatif ditimbulkan dari spotanitas penari yang tidak sadarkan diri atau kesurupan. Beberapa tokoh penari yang menggunakan gerak nonrepresentatif yaitu pemain Kuda Lumping, pemain kuda kepang, pemain topeng, pemain barongan, sintren, dan demit. Berbeda dengan ragam gerak penari Sokoaji yang terdiri dari: 1) srisig, 2) besut, 3) dolanan sampur, 4) seblakan pundak, 5) ukel puter, 6) sembahan.

Rias dan busana kesenian Kuda Lumping Sokoaji disesuaikan dengan peran atau tokoh yang dibawakan dan tentunya mengutamakan kenyamanan peran atau tokoh yang dibawakan seperti: rias korektif bagi penari perempuan, dan rias karakter bagi penari topeng dan Kuda Lumping. Tata busana pemain Kuda Lumping terdiri dari rompi hitam berbahan bludru dengan motif macan, celana hitam berbahan satin, iket, dan jarik parang putih.

Iringan di Paguyuban Genjring Sokoaji menggunakan seperangkat gamelan yang berlaras pelog untuk mengiringi pertunjukan Kuda Lumping Sokoaji. Selain gamelan, Paguyuban Genjring Sokoaji juga memiliki iringan ekternal yaitu angklung. Paguyuban
Genjring Sokoaji juga sudah memiliki lagu dan tari Sokoaji yang diciptakan oleh Bapak Daram dengan dibantu anggota lain.

Pementasan kesenian Kuda Lumping di Paguyuban Genjring Sokoaji di lapangan atau lahan kosong. Pertunjukan kesenian Kuda Lumping Sokoaji menggunakan tata lampu yang sederhana. Pertunjukan pada siang hari, biasanya kesenian Kuda Lumping Sokoaji memanfaatkan cahaya matahari tanpa tambahan lampu. Berbeda dengan pertunjukan pada malam hari, kesenian Kuda Lumping memerlukan beberapa lampu untuk penerang untuk pengrawit dan pemain lainya.

Properti yang digunakan di pertunjukan kesenian Kuda Lumping Sokoaji merupakan properti dengan jenis dance property. Dance Property yang digunakan dalam pertunjukan kesenian Kuda Lumping Sokoaji yaitu: Kuda Lumping, kuda kepang, topeng, barongan, dan kurungan ayam. Kuda kepang merupakan properti yang terbuat dari bambu yang ditekuk menyerupai kuda ditambah dengan tali rafia sebagai penggambaran rambut dan ekor kuda. Properti Kuda Lumping yaitu properti yang terbuat dari anyaman bambu yang dibentuk seperti kuda. Properti topeng di Paguyuban Genjring Sokoaji yaitu topeng macanan yang terbuat dari kayu yang dihiasi dengan gimbalan. Cara menggunakan topeng macanan yaitu menggigit karet yang ada di topeng macanan. Properti barongan di Paguyuban Genjring Sokoaji memiliki persamaan dengan barongan di daerah lain yaitu memerlukan dua orang untuk memakai barongan ini. Orang pertama pada bagian kepala memegang kepala barong yang terbuat dari kayu, orang kedua menjadi ekor barongan yang berjalan mengikuti kepala barongan.

Kurungan ayam merupakan properti Paguyuban Genjring Sokoaji saat keluarnya sintren. Sintren salah satu kesenian khas dari Pekalongan menggambarkan seseorang yang sedang dalam fase damai dengan dirinya sendiri di dalam kegelapan. Ditandai dengan kacamata yang digunakan oleh sintren, manusia tidak bisa melihat apapun hanya 
gelap yang manusia temui. Perbedaan sintren di kesenian Kuda Lumping Sokoaji yaitu pemain sintren merupakan seorang laki-laki.

\section{Proses Enkulturasi}

Peneliti dalam menganalisa proses enkulturasi, mengambil tiga subjek sebagai sumber data dan diteliti proses enkulturasinya. Pemilihan tiga subjek sumber data berdasarkan peran subjek di Paguyuban Genjring Sokoaji, seperti halnya: Poerwanto selaku pemain Kuda Lumping, Nikma Maulandari selaku penari, dan Kiki Sunardi selaku pemusik.

Terdapat proses enkulturasi budaya digolongkan sesuai dengan sumber budaya yang diwariskan yaitu: proses enkulturasi secara tradisional melalui: keluarga, masyarakat, lembaga adat, dan proses enkulturasi modern melalui organisasi dan kelompok sosial, dan media massa. Proses enkulturasi yanag terjadi di Paguyuban Genjring Sokoaji yaitu secara tradisional dan modern.

Proses enkulturasi secara tradisional melalui keluarga dirasakan oleh Kiki Sunardi sebagai anak dari pawang Kuda Lumping Sokoaji. Kiki seringkali diajak langsung melihat pertunjukan kesenian Kuda Lumping yang membawa Kiki sekarang ini menjadi pengrawit. Berbeda dengan Poerwanto dan Nikma yang tidak memiliki garis keturunan dari keluarga namun seringkali melihat pertunjukan kesenian Kuda Lumping, sekarang ini sudah menjadi pemain Kuda Lumping dan penari di Paguyuban Genjring Sokoaji.

Proses enkulturasi melalui masyarakat ditandai dengan usaha masyarakat untuk mendukung proses enkulturasi kesenian Kuda Lumping di Paguyuban Genjring Sokoaji yaitu: Pertama, Peminjaman Sound pada saat latihan. Peminjaman sound pada saat latihan merupakan tindakan yang menandakan bahwa masyarakat Desa Sokoyoso khususnya warga sekitar paguyuban menerima adanya keberadaan Paguyuban Genjring Sokoaji.

Kedua, Partisipasi Masyarakat

Desa Sokoyoso saat Pementasan
Kesenian Kuda Lumping Sokoaji Pementasan Kesenian Kuda Lumping Sokoaji seharusnya menjadi sesuatu yang sudah sering dilihat bagi masyarakat Desa Sokoyoso. Partisipasi masyarakat Desa Sokoyoso sebagai penonton masih tinggi walaupun masyarakat Desa Sokoyoso sudah sering melihatnya. Masyarakat merupakan unsur pendukung suatu kesenian tetap bertahan. Sebagaimana masyarakat Desa Sokoyoso yang memiliki satu kesenian rakyat yaitu kesenian Kuda Lumping akan terus dilestarikan. Desa Sokoyoso telah menjadikan Paguyuban Genjring Sokoaji sebagai ikon Desa Sokoyoso.

Selain proses enkulturasi secara tradisional, peneliti menemukan proses lain yaitu melalui proses pembelajaran. Proses pembelajaran yang dialami Kiki, Poerwanto, dan Nikma berbeda-beda. Proses enkulturasi melalui pembelajaran oleh Poerwanto yaitu: 1) berpuasa Senin Kamis, 2) mandi bunga tujuh rupa, 3) menjadi penjaga pentas, 4) Latihan Tenaga Dalam.

Proses enkulturasi melalui pembelajaran dialami Kiki Sunardi yaitu: 1) melihat, 2) meniru, 3) latihan. Proses enkulturasi melalui pembelajaran oleh Nikma Maulandari yaitu: proses latihan yang didalamnya berisi diskusi serta faktor pendukung dan penghambat pada saat latihan. Enkulturasi melalui proses pembelajaran dilakukan melalui latihan dan pertunjukan. Proses latihan yang dilakukan secara terstruktur bertujuan agar proses penyampaian materi terjadi secara efektif. Proses pembelajaran pada pertunjukan juga dilakukan agar penjaga pentas dapat memahami teknik menjadi pemain Kuda Lumping sebelum menjadi pemain Kuda Lumping sebenarnya.

\section{Pola Enkulturasi}

Cavalli Sforza dan Feldman mengemukakan dua jenis pola pewarisan "Vertical Transmission" dan "Horizontal Transmission" (dalam Rochmat 2013: 3334). "Vertical Transmission" (Pewarisan Tegak) ialah sistem pewarisan yang berlangsung melalui mekanisme genetik yang diturunkan dari generasi ke generasi dari orang tua kepada anak cucu. 
Orang tua mewariskan nilai, keterampilan, nilai budaya, motif budaya kepada anak cucu. Pewarisan tegak disebut juga "Biological Transmission" sedangkan "Horizontal Transmission" atau pewarisan miring. "Horizontal Transmission" berlangsung melalui lembaga pendidikan seperti sekolahsekolah atau sanggar-sanggar. Pewarisan miring terjadi ketika seseorang belajar dari orang dewasa atau lembaga-lembaga tanpa memandang apakah hal itu terjadi dalam budaya sendiri atau tidak.

Pola enkulturasi yang terjadi di

Paguyuban Genjring Sokoaji menggunakan pola pewarisan miring yaitu Horizontal Transmission. Sebagian besar pengetahuan mengenai Kuda Lumping didapatkan anggota paguyuban dari lingkungan keluarganya, misalkan: orangtua atau saudara terdekat. Pola pewarisan miring memang efektif ketika anggota keluarga ikut mendorong pewarisan nilai, ketrampilan, budaya, norma dengan anak cucunya. Pola pewarisan miring biasanya juga terjadi karena ketidak sengajaan yang menjadi sebuah kebiasaan.

Proses enkulturasi Poerwanto, Kiki, dan Nikma di Paguyuban Genjring Sokoaji dapat dikatakan melalui sistem "Horizontal Transmission" atau pewarisan miring. Sistem Pewarisan Poerwanto, Kiki, dan Nikma berlangsung di Paguyuban Genjring Sokoaji dan terdapat guru di masing-masing bidang, seperti Ari Johani sebagai pelatih pemain Kuda Lumping, Bapak Daram selaku guru karawitan, dan Bapak Bagus sebagai guru tari. Proses pewarisan berjalan dengan lancar dengan adanya proses pembelajaran yang dilakukan secara tidak langsung. Misalnya, pada saat berlatih akan terjadi proses pembelajaran seperti: melihat, meniru, mendengar, serta mencoba.

\section{SIMPULAN}

Kesenian Kuda Lumping Sokoaji merupakan kesenian rakyat yang sudah ada sejak tahun 1995 di Desa Sokoyoso Kecamatan Kajen Kabupaten Pekalongan. Bentuk pertunjukan kesenian Kuda Lumping Sokoaji yang sering dipentaskan merupakan hasil dari proses enkulturasi secara turun temurun yang telah terjadi sejak tahun 1995 hingga sekarang. Proses enkulturasi di Paguyuban Genjring Sokoaji terjadi secara tradisional dan melalui pembelajaran. Proses enkulturasi di Paguyuban Genjring Sokoaji secara tradisional melalui keluarga dan lingkungan masyarakat. Proses enkulturasi melalui pembelajaran di Paguyuban Genjring Sokoaji terjadi ketika latihan dan pementasan atau pertunjukan.

Pandangan peneliti terhadap proses enkulturasi kesenian Kuda Lumping Sokoaji kedepan yaitu kesenian Kuda Lumping Sokoaji akan tetap bertahan dan eksis di Kecamatan Kajen Kabupaten Pekalongan. Namun dengan sarana prasarana yang kurang memadai, dapat menghambat proses enkulturasi yang mengakibatkan berkurangnya regenerasi anggota Paguyuban Genjring Sokoaji.

Saran peneliti bagi Paguyuban Genjring Kuda Lumping Sokoaji yaitu agar melengkapi sarana dan prasarana latihan atau pentas untuk meningkatkan kualitas pertunjukan kesenian Kuda Lumping Sokoaji. Diharapkan adanya kerjasama dengan Pemerintah Kabupaten Pekalongan agar lebih memperhatikan kesenian yang ada di Kabupaten Pekalongan sebagai warisan budaya. Selain itu, saran peneliti bagi anggota Paguyuban Genjring Sokoaji agar lebih meningkatkan proses regenerasi dan kualitas agar kesenian Kuda Lumping Sokoaji tidak hanya eksis di Kecamatan Kajen Kabupaten Pekalongan tetapi dapat bersaing di luar Kabupaten Pekalongan.

\section{DAFTAR PUSTAKA}

Cahyono, Agus. 2006. Pola Pewarisan Nilai-Nilai Kesenian Tayub. Jurnal Harmonia, Vol. VII No.1/ Januari-April 2006. Semarang: Jurusan Sendratasik Fakultas Bahasa dan Seni UNNES.

Jazuli, M. (2016). Peta Dunia Seni Tari. Semarang: CV Farishma Indonesia. 
Kadiran. (2004). Pewarisan Budaya Dan Kepribadian. Humaniora, 16(1), 10-11.

Poerwanto, Hari. (2000). Kebudayaan

Lingkungan dalam Perspektif Antropologi. Yogyakarta: Pustaka Pelajar.

Rochmat, Nur. 2013. Pewarisan Tari Topeng Gaya Dermayon: Studi Kasus Gaya Rasinah. Resital, Vol XIV/ No. 1/Juni 2013. Bandung: Jurusan Tari Sekolah Tinggi Seni Indonesia (STSI).

Sumaryono. 2011. Antropologi Tari Dalam Perspektif Indonesia. Yogyakarta: ISI Yogyakarta. Triyanto. 2015. Perkeramikan Mayong Lor Jepara: hasil Enkulturasi Dalam Keluarga Komunitas Perajin. Imajinasi, Vol. IX No. 1/ Januari 2015. Semarang: Fakultas Bahasa dan Seni UNNES

Sunaryo. 1989. Strategi Mengajar Dalam Pengajaran Ilmu Pengetahuan Sosial. Jakarta: Depdikbud. 